Bangladesh J. Bot. 38(1): 77-85, 2009 (June)

\title{
PHYSICOCHEMICAL ASPECTS AND PHYTOPLANKTON OF THE RIVER SHITALAKHYA RECEIVING PHARMACEUTICAL EFFLUENTS
}

\author{
Z. N. Tahmida Begum and Dilara Khanam \\ Department of Botany, University of Dhaka, Dhaka-1000, Bangladesh
}

Keywords: Phytoplankton, Pharmaceutical effluents, Shitalakhya River, Bangladesh

\begin{abstract}
Phytoplankton from a part of the Shitalakhya river receiving effluents from a pharmaceutical industry have been studied. A total of 78 taxa were identified of which 14 belonged to Cyanophyceae, 11 Chlorophyceae, 20 Euglenophyceae and 33 Bacillariophyceae. The water body was mostly alkaline (6.6 8.0) and showed a wide range of variation in conductivity (135 - $4768 \mu \mathrm{S} / \mathrm{cm}$ ), DO (anoxia to $15 \mathrm{mg} / \mathrm{l}$ ), free$\mathrm{CO}_{2}(3-29 \mathrm{mg} / \mathrm{l})$, bicarbonate alkalinity $(49-355 \mathrm{mg} / \mathrm{l})$, BOD $(8-1800 \mathrm{mg} / \mathrm{l})$ at different locations. Pharmaceutical effluents appeared to affect diversity of phytoplankton. Three diatoms namely Fragilaria brevistriata Grun., F. construens (Ehr.) Grun. and Navicula oblonga Kütz. present in the area, are described as new for Bangladesh.
\end{abstract}

\section{Introduction}

Algae are good indicators for water quality (Palmer 1959, Patrick 1973, Hynes and Pentelow 1978, Trainor 1984). In Bangladesh, Islam and Zaman (1975), Islam et al. (1991), Khondker et al. (1990) and Begum and Hossain (1993) studied some running and stagnant freshwater habitats using phytoplankton species as indicators. In the country, most of the industries like textiles, pharmaceuticals, tanneries, paper mills and oil refineries are situated on the bank of rivers and discharge effluents directly into it. Besides, varieties of chemical fertilizers and residues of pesticides are also incorporated in the river systems via leaching and as wash outs. These pollutants inhibit the growth of aquatic flora and fauna. In Bangladesh, a very few reports do exist on the effects of industrial effluents on phytoplankton (Begum and Hossain 1993, Begum 2008). The present study was therefore undertaken to study the effects of pharmaceutical effluents on the phytoplankton diversity and abundance in the river Shitalakhya, Narayanganj, Bangladesh.

\section{Material and Methods}

The study was carried out in a part of the river Shitalakhya, Naryanganj, receiving effluents from pharmaceutical industry. Four stations along the stretch of the effluent channel were selected for carrying out the sampling. These were designated hereinafter $S_{1}, S_{2}, S_{3}$ and $S_{4}$ where $S_{1}$ is located near the point of release of effluents. Three replicates were taken from each station. Water samples were collected fortnightly from November, 1994 to October, 1995 at a depth of about 15$25 \mathrm{~cm}$ from each station between 9.00 and 10.00 a.m. $\mathrm{pH}$ and water temperature were measured in situ by using a CD-300 digital portable $\mathrm{pH}$ meter and a mercury centigrade thermometer, respectively. Dissolved oxygen (DO), BOD and free- $\mathrm{CO}_{2}$ were measured following APHA (1976). Measurement of biocarbonate alkalinity (BA) was carried out after Gerrath and Denny (1979). For conductivity, a Blackman conductivity meter (Model No. 4070, range 0-20 mS) was used. For biological analyses collection, preservation and qualitative assessment of phytoplankton were done following Khondker et al. (1988) and Johansen (1940). Literatures consulted are shown in Table 2. Classification proposed by Bold and Wynne (1985) was followed. 


\section{Results and Discussion}

Physicochemical variables in the four sampling stations are presented in Table 1 . The $\mathrm{pH}$ range from 6.6 to 8.0, and desmids were not recorded, an observation similar to that of Khondker et al. (1990). On the contrary desmids were recorded in the pond where the $\mathrm{pH}$ ranged from 5.45 to 7.28 (Begum and Hassain 1993). Conductivity showed a wide variation in all the four stations ranging from $135 \mu \mathrm{S} / \mathrm{cm}$ in early September to $4768 \mu \mathrm{S} / \mathrm{cm}$ in early November. The value is about four times higher than that reported from a polluted pond (Khondker et al. 1990). Except $S_{1}$, the range of DO was lower than the values reported in polluted waters. As expected lowest range of BOD (8.0 -433.0 mg/l) was observed in $\mathrm{S}_{1}$ (Table 1 ).

Table 1. Range of physicochemical variables recorded in four sampling stations of the Shitalakhya river, near a pharmaceutical industry.

\begin{tabular}{lcccc}
\hline \multirow{2}{*}{ Parameters } & \multicolumn{3}{c}{ Sampling stations } \\
\cline { 2 - 4 } & $\mathrm{S}_{1}$ & $\mathrm{~S}_{2}$ & $\mathrm{~S}_{3}$ & $\mathrm{~S}_{4}$ \\
\hline Water temp. in ${ }^{\circ} \mathrm{C}$ & $24-40$ & $22-42$ & $20-42$ & $18-38$ \\
$\mathrm{pH}$ & $6.6-7.5$ & $7.0-7.5$ & $7.0-8.0$ & $7.0-8.0$ \\
Conductivity $(\mu \mathrm{S} / \mathrm{cm})$ & $272-489$ & $292-645$ & $292-683$ & $135-4768$ \\
DO (mg/l) & $3.0-15.0$ & $0.0-8.0$ & $1.3-10.0$ & $0.0-8.0$ \\
Free $\mathrm{CO}_{2}(\mathrm{mg} / \mathrm{l})$ & $7-23$ & $7-21$ & $3-25$ & $5-29$ \\
Biocarbonate alkalinity (mg/l) & $81-182$ & $84-192$ & $65.2-264$ & $49-355$ \\
BOD (mg/l) & $8-433$ & $10-1620$ & $14-1800$ & $13-1300$ \\
\hline
\end{tabular}

$\mathrm{S}_{1}=$ station of the river nearest to the point of direct discharge from the industry, $\mathrm{S}_{2}=$ station about 50 feet away from $\mathrm{S}_{1}, \mathrm{~S}_{3}=$ station about 150 feet away from $\mathrm{S}_{2}, \mathrm{~S}_{4}=$ far from $\mathrm{S}_{1}$.

Members of Bacillariophyceae were found to be dominant. More or less similar observations were made by Begum and Hossain (1993). Observation of euglenoid bloom in anoxic condition in the month of March is in agreement with the observation of Hegde and Bharati (1986), Hickmen and Pen (1997) and Begum and Hossain (1993). The taxa recorded in the present study along with their dimension and abundance in different stations are given in Table 2 in which the abundance of three species of Merismopedia and Microcystis aeruginosa, Oscillatoria amphibia, O. ornata, O. subbrevis, Anabaena circinalis and A. flos-aquae is evident. These species seem to be resistant to polluted environment. Begum and Hossain (1993) and Begum (2008) also observed more or less similar abundanc of these species in a pond receiving effluents from two textile industries. Similarly chlorophycean phytoplankton like Eudorina elegans, Scenedesmus acuminatus, S. arcuatus are common in this habitat. Previously Islam and Begum (1970) and Begum (2008) reported their abundance in polluted water bodies and textile industrial effluents, respectively. With a few exceptions, among all the groups of phytoplankton recorded, Euglenophyceae showed dominance in all the four stations (Table 2). Similar observation was also made earlier in two polluted ponds by Islam et al. (1990) and in textile industrial effluents by Begum and Hossain (1993). On the contrary lowest representation by the members of Chlorophyceae indicates that this group is more sensitive to the pollutants discharged by the pharmaceutical industry. Similar observation was made by Islam and Khatun (1966). The members of Bacillariophyceae appear to be best adaptated in the polluted habitat (Table 2) as indicated by 36 genera out of 78 . Their lowest count was recorded when the pond water was anaerobic. The present investigation revealed that the effluents discharged from pharmaceutical industries are more harmful than those from the textile industries as indicated by only 78 taxa of phytoplanktonic algae compared to 308 taxa (Begum and Hossain 1993). 
Table 2. List of the recorded phytoplankton together with their dimension, abundance and source of identification. $\mathbf{l}$. = long; b. $=$ broad, $*_{+}=$few; $++=$common; $+++=$very common.

\begin{tabular}{|c|c|c|c|c|}
\hline Species & Stations & $\begin{array}{l}\text { Abun- } \\
\text { dance* }\end{array}$ & Dimension $(\mu \mathrm{m})$ & References \\
\hline \multicolumn{5}{|c|}{ Class: Cyanophyceae; Order: Chroococcales; Family: Chroococcaceae } \\
\hline $\begin{array}{l}\text { Merismopedia elegans A. Br. } \\
\text { in Kütz. }\end{array}$ & 1,2 & + & $\begin{array}{l}\text { Colonies } 4.5-5.0 \text { l., } \\
\text { 3.0-4.0 b. }\end{array}$ & Islam and Aziz 1979 \\
\hline $\begin{array}{l}\text { Merismopedia minima Beck } \\
\text { in Beck and Zahlbruchner }\end{array}$ & 1,2 & ++ & $\begin{array}{l}\text { Cells } 0.5-0.6 \text { b., groups } \\
\text { of } 4 \text { cells } 2.0-3.0 \text { (dia.) }\end{array}$ & Islam and Nahar 1967 \\
\hline $\begin{array}{l}\text { Merismopedia punctata } \\
\text { Meyen in Wiegmann }\end{array}$ & 1,2 & ++ & Cells 1.5 l., 1.0 b. & Khondker et al. 2006 \\
\hline Microcystis aeruginosa Kütz. & 1 & ++ & Cells 3.0-7.0 (dia.) & $\begin{array}{l}\text { Islam and Nahar 1967, } \\
\text { Islam and Uddin } 1977\end{array}$ \\
\hline $\begin{array}{l}\text { Microcystis flos-aquae } \\
\text { (Wittr.) Kirchner in Engler }\end{array}$ & 3,4 & ++ & Cells 3.0-7.0 (dia.) & $\begin{array}{l}\text { Islam and Nahar 1967, } \\
\text { Islam and Zaman } 1975\end{array}$ \\
\hline
\end{tabular}
and Prantl

Order: Oscillatoriales, Family: Oscillatoriaceae

Oscillatoria amphibia Ag ex $\quad 3 \quad+++$ Gom.

Oscillatoria boryana Bory ex

Gom.

Oscillatoria limnetica Lemm.

$3,4 \quad++$

Cells 2.0 l., 3.5-4.0 b

$2,3 \quad++$

Cells 2.5-5.0 l., $1.5-2.0 \mathrm{~b}$

Oscillatoria ornata Kütz. ex

Gom.

$2,3+++$

Cells 2.0-5.0 l., 7.0-9.0 b.

Oscillatoria sancta (Kütz.)

Gom.

1, 3, $4 \quad++\quad$ Cells 2.3-6.1 l., 9.2-16.0 b.

Oscillatoria subbrevis

Schmidle

1-3 +++ Cells 1.0-2.0 1., 5-6 b.

Family: Nostocaceae

Anabaena circinalis Rabenh. ex Born. et Flah.

3-4 +++

Trichome 5-8 b., Cells

7.0-10.0 l., 5.0-6.0 b. Heterocysts 7-11 b.

Anabaena constricta (Szafer) Geitler

2, $3 \quad++$

Cells 2.5-11.4 l., 3.5$15.0 \mathrm{~b}$.

Anabaena flos-aquae (Lyngb.) 1-4 +++

Heterocysts 7.8 l., 6.0-7.0 b., Cells 5-6 b.
Islam and Nahar 1967, Aziz and Islam 1986

Islam and Irfanullah 2005, Khondker et al. 2006, Begum 2008

Islam and Nahar 1967

Aziz and Tanbir 1999, Islam and Irfanullah 2005, Begum 2008

Islam and Nahar 1967, Islam and Irfanullah 2005

Aziz and Islam 1986, Begum 2008

Islam and Khatun 1967, Islam and Irfanullah 2005, Begum 2008

Begum 2008

Islam and Nahar 1967, Begum 2008

Class: Chlorophyceae, Order: Vovlvocales, Family: Chlamydomonadaceae

Chlamydomonas gloeogama

3

Cells 14.0 l., 8.0 b.

Islam and Khondker 1997

Kors. in Pascher 
(Contd.)

\begin{tabular}{|c|c|c|c|c|}
\hline Species & Stations & $\begin{array}{l}\text { Abun- } \\
\text { dance* }\end{array}$ & Dimension $(\mu \mathrm{m})$ & References \\
\hline \multicolumn{5}{|l|}{ Family: Volvocaceae } \\
\hline Pandorina morum (Müller) Bory & 1 & ++ & $\begin{array}{l}\text { Colonies 30-41l., } \\
\text { 20-33 b.; } \\
\text { Cells } 9.0-13.0 \text { l., } \\
\text { 6.6-10.0 b. }\end{array}$ & $\begin{array}{l}\text { Islam and Khatun 1966, } \\
\text { Begum } 2008\end{array}$ \\
\hline Eudorina elegans Ehr. & 1,2 & +++ & Cells 7.0-11.7 (dia.) & Islam and Khatun 1966 \\
\hline \multicolumn{5}{|c|}{ Order: Chlorococcales, Family: Oocystaceae } \\
\hline Chlorella vulgaris Beyerinck & 1,2 & ++ & $\begin{array}{l}\text { Cells 5.5-9.9 l., } \\
4.5-13.0 \text { b. }\end{array}$ & $\begin{array}{l}\text { Islam and Khatun 1966, } \\
\text { Islam and Begum 1970, } \\
\text { Aziz and Tanbir } 2003\end{array}$ \\
\hline \multicolumn{5}{|l|}{ Family: Scenedesmaceae } \\
\hline $\begin{array}{l}\text { Scenedesmus acuminatus } \\
\text { (Lagerh.) Chodat }\end{array}$ & $1-4$ & +++ & $\begin{array}{l}\text { Colonies } 21.6 \text { l.; } \\
\text { Cells } 14.8-20.2 \text { l., } \\
\text { 2.7-6.6 b. }\end{array}$ & $\begin{array}{l}\text { Islam and Khatun 1966, } \\
\text { Islam and Begum 1970, } \\
\text { Islam and Zaman } 1975\end{array}$ \\
\hline Scenedesmus arcuatus Lemm. & $1-4$ & +++ & $\begin{array}{l}\text { Cells 6.6-14.3 l., } \\
4.4-8.8 \text { b. }\end{array}$ & $\begin{array}{l}\text { Islam and Khatun 1966, } \\
\text { Islam and Begum 1970, } \\
\text { Begum } 2008\end{array}$ \\
\hline Scenedesmus brasiliensis Bohlin & 1,4 & + & $\begin{array}{l}\text { Colonies } 21-27 \text { l., } \\
\text { cells } 11.0-22.3 \text { l., } \\
4.4-7.4 \text { b. }\end{array}$ & $\begin{array}{l}\text { Islam and Khatun 1966, } \\
\text { Islam and Begum } 1970\end{array}$ \\
\hline \multicolumn{5}{|c|}{ Order: Chlorellales, Family: Chlorellaceae } \\
\hline Teträdron regulare Kütz. & 1,2 & + & $\begin{array}{l}\text { Cells } 15.5-57.4 \text { l., } \\
50.7 \text { b. (with spine) }\end{array}$ & $\begin{array}{l}\text { Islam and Begum 1970, } \\
\text { Islam and Irfanullah } \\
\text { 2005, Begum } 2008\end{array}$ \\
\hline $\begin{array}{l}\text { Teträdron trigonum (Nägeli) } \\
\text { Hansgirg }\end{array}$ & $1-4$ & +++ & $\begin{array}{l}\text { Cells } 11.2-22.0 \text { l., } \\
8.6-22.0 \text { b. }\end{array}$ & $\begin{array}{l}\text { Islam and Begum 1970, } \\
\text { Begum } 2008\end{array}$ \\
\hline \multicolumn{5}{|l|}{ Family: Coelastraceae } \\
\hline $\begin{array}{l}\text { Closteriopsis longissima var. } \\
\text { tropica West \& West }\end{array}$ & 1,2 & ++ & Cells 97.9 l., 4.4 b. & Islam and Begum 1970 \\
\hline Actinastrum hantzschii Lagerh. & $1-4$ & + & $\begin{array}{l}\text { Cells 8.8-19.6 l., } \\
2.2-4.2 \text { b. }\end{array}$ & $\begin{array}{l}\text { Islam and Khatun 1966, } \\
\text { Islam and Begum } 1970\end{array}$ \\
\hline \multicolumn{5}{|c|}{ Class: Euglenophyceae, Order: Eutreptiales, Family: Eutraeptiaceae } \\
\hline Eutreptia sp. & 3 & + & $\begin{array}{l}\text { Cells } 22.8-42.75 \text { l., } \\
\text { 8.5-14.25 b. }\end{array}$ & Islam et al. 1991 \\
\hline \multicolumn{5}{|c|}{ Order: Euglenales, Family: Euglenaceae } \\
\hline Euglena acus (Müller) Ehr. & $1-4$ & +++ & $\begin{array}{l}\text { Cells } 76.0-250.0 \text { l., } \\
\text { 5.7-14.3 b. }\end{array}$ & $\begin{array}{l}\text { Islam and Khatun 1966, } \\
\text { Islam et al. } 1991\end{array}$ \\
\hline Euglena chlamydophora Mainx & $1-4$ & +++ & Cells 54.1 l., $17.1 \mathrm{~b}$. & Islam et al. 1991 \\
\hline Euglena clara Skuja & 4 & ++ & Cells 61.0 l., 40.2 b. & Islam et al. 1991 \\
\hline
\end{tabular}


(Contd.)

\begin{tabular}{|c|c|c|c|c|}
\hline Species & Stations & $\begin{array}{l}\text { Abun- } \\
\text { dance* }\end{array}$ & Dimension $(\mu \mathrm{m})$ & References \\
\hline \multicolumn{5}{|c|}{ Order: Euglenales, Family: Euglenaceae } \\
\hline $\begin{array}{l}\text { Euglena granulata (Klebs) Fr. } \\
\text { Schmitz }\end{array}$ & 1 & ++ & $\begin{array}{l}\text { Cells 37.0-64.5 l., } \\
22.8-28.5 \text { b. }\end{array}$ & $\begin{array}{l}\text { Islam and Khatun 1966, } \\
\text { Islam et al. } 1991\end{array}$ \\
\hline Euglena pisciformis Klebs & 1 & +++ & $\begin{array}{l}\text { Cells 24.0-82.0 l., } \\
7.0-11.0 \text { b. }\end{array}$ & $\begin{array}{l}\text { Islam et al. 1991, Islam } \\
\text { and Irfanullah } 2005\end{array}$ \\
\hline Euglena proxima Dangeard & 3 & + & Cells 54.1 l., 14.2 b. & Islam et al. 1991 \\
\hline Euglena variabilis Klebs & 2,3 & +++ & $\begin{array}{l}\text { Cell } 76.75 \text { l., } \\
14.2-28.5 \text { b. }\end{array}$ & Islam et al. 1991 \\
\hline $\begin{array}{l}\text { Trachelomonas armata (Ehr.) } \\
\text { Stein }\end{array}$ & 1 & + & $\begin{array}{l}\text { Lorica } 12-14 \text { l., } \\
21.0-29.6 \text { b. }\end{array}$ & $\begin{array}{l}\text { Islam and } \\
\text { Moniruzzaman 1981, } \\
\text { Islam and Irfanullah } \\
2005\end{array}$ \\
\hline $\begin{array}{l}\text { Trachelomonas hispida (Perty) } \\
\text { Stein }\end{array}$ & $1-4$ & +++ & $\begin{array}{l}\text { Lorica 21-36 l., } \\
15-25 \text { b. }\end{array}$ & $\begin{array}{l}\text { Islam and } \\
\text { Moniruzzaman 1981, } \\
\text { Islam and Alfasane } \\
\text { 2004, Islam and } \\
\text { Irfanullah } 2005\end{array}$ \\
\hline $\begin{array}{l}\text { Trachelomonas hispida } \\
\text { var. coronata Lemm. }\end{array}$ & $2-4$ & ++ & Lorica 38 l., 22-25 b. & $\begin{array}{l}\text { Islam and } \\
\text { Moniruzzaman } 1981\end{array}$ \\
\hline $\begin{array}{l}\text { Trachelomonas hispida } \\
\text { var. punctata Lemm. }\end{array}$ & $1-4$ & +++ & $\begin{array}{l}\text { Lorica } 25-29 \text { l., } \\
17-26 \text { b. }\end{array}$ & $\begin{array}{l}\text { Islam and } \\
\text { Moniruzzaman 1981, } \\
\text { Islam and Irfanullah } \\
2005\end{array}$ \\
\hline $\begin{array}{l}\text { Trachelomonas mucosa } \\
\text { var. brevicollis Skv. }\end{array}$ & 1 & + & Lorica 18.0 l., 14.5 b. & $\begin{array}{l}\text { Islam and } \\
\text { Moniruzzaman } 1981\end{array}$ \\
\hline Trachelomonas oblonga Lemm. & $1-4$ & +++ & $\begin{array}{l}\text { Lorica } 11-16 \text { l., } \\
\text { 7.5-12.4 b. }\end{array}$ & $\begin{array}{l}\text { Islam and } \\
\text { Moniruzzaman 1981, } \\
\text { Islam and Irfanullah } \\
2005\end{array}$ \\
\hline $\begin{array}{l}\text { Trachelomonas oblonga Lemm. } \\
\text { fa. ovata Defl. }\end{array}$ & 1 & + & Lorica 17.7 l., 13.6 b. & $\begin{array}{l}\text { Islam and } \\
\text { Moniruzzaman } 1981\end{array}$ \\
\hline Trachelomonas playfairii Defl. & $1-4$ & + & $\begin{array}{l}\text { Lorica } 23-25 \text { l., } \\
16-18 \text { b. }\end{array}$ & $\begin{array}{l}\text { Islam and } \\
\text { Moniruzzaman } 1981\end{array}$ \\
\hline $\begin{array}{l}\text { Trachelomonas rotunda Swir. } \\
\text { emend Defl. }\end{array}$ & $1-4$ & +++ & $\begin{array}{l}\text { Lorica } 12.0-22.5 \text { l., } \\
14-25 \text { b. }\end{array}$ & $\begin{array}{l}\text { Islam and } \\
\text { Moniruzzaman } 1981\end{array}$ \\
\hline Phacus caudatus Hubn. & 3 & + & $\begin{array}{l}\text { Cells 18.4-29.7 l., } \\
\text { 8.5-18.2 b. }\end{array}$ & $\begin{array}{l}\text { Islam et al. 1991, Islam } \\
\text { and Irfanullah } 2005\end{array}$ \\
\hline Phacus circumflexus Pochm. & $2-3$ & + & Cells 76.9 l., 39.9b. & $\begin{array}{l}\text { Islam et al. 1991, Islam } \\
\text { and Alfasane } 2002\end{array}$ \\
\hline Phacus curvicauda Swirenko & 4 & +++ & $\begin{array}{l}\text { Cells 30.4-80.0 l., } \\
\text { 24.3-47.0 b. }\end{array}$ & $\begin{array}{l}\text { Islam and Khatun 1966, } \\
\text { Islam et al. 1991, Islam } \\
\text { and Irfanullah 2005 }\end{array}$ \\
\hline
\end{tabular}




\begin{tabular}{|c|c|c|c|c|}
\hline Species & Stations & $\begin{array}{l}\text { Abun- } \\
\text { dance* }\end{array}$ & Dimension $(\mu \mathrm{m})$ & References \\
\hline \multicolumn{5}{|c|}{ Class: Bacillariophyceae, Order: Centrales, Family: Melosiraceae } \\
\hline Melosira granulata (Ehr.) Ralfs & $1-4$ & +++ & $\begin{array}{l}\text { Cells } 11.5-15.5 \text { l., } 8.0 \\
\text { b. }\end{array}$ & $\begin{array}{l}\text { Islam and Aziz 1977, } \\
\text { Islam and Irfanullah } \\
2005\end{array}$ \\
\hline Melosira undulata (Ehr.) Kütz. & 2 & + & Cells 20-22 l., 19 b. & Islam and Aziz 1975 \\
\hline Melosira varians C. Ag. & $1-3$ & ++ & $\begin{array}{l}\text { Cells 2.0-49.98 l., } \\
\text { 5.44-25.0 b. }\end{array}$ & $\begin{array}{l}\text { Islam and Aziz 1975, } \\
\text { Islam and Haroon } 1975\end{array}$ \\
\hline \multicolumn{5}{|l|}{ Family: Coscinodiscaceae } \\
\hline $\begin{array}{l}\text { Coscinodiscus lacustris Grove } \\
\text { Rattray. }\end{array}$ & $1-3$ & ++ & Cells 33-34 dia. & Islam and Haroon 1975 \\
\hline \multicolumn{5}{|c|}{ Order: Pennales, Family: Fragilariaceae } \\
\hline Fragilaria brevistriata Grun. & $1-3$ & ++ & Cells 7-25 l., 3-5 b. & Germain 1981 \\
\hline Fragilaria capucina Desm. & $2-4$ & +++ & Cells 43.5 l., 4.3 b. & Islam and Haroon 1975 \\
\hline $\begin{array}{l}\text { Fragilaria construens (Ehr.) } \\
\text { Grun. }\end{array}$ & 3,4 & ++ & Cells 14-16 l., 3-9 b. & Germain 1981 \\
\hline Fragilaria crotonensis Kitton & 1 & + & Cells 40-150 l., 70 b. & $\begin{array}{l}\text { Germain 1981, Aziz } \\
\text { and Tanbir } 2003\end{array}$ \\
\hline Fragilaria virescens Ralfs & $1-4$ & +++ & Cells 42-79 l., 5-8 b. & $\begin{array}{l}\text { Germain 1981, Nahar } \\
2001 \text { (Pers. Comm.) }\end{array}$ \\
\hline Synedra acus Kütz., Kieselschal. & $1-4$ & +++ & $\begin{array}{l}\text { Cells } 148.8 \text { l., } 7.2 \text { b. } \\
\text { (at the middle) }\end{array}$ & Islam and Haroon 1975 \\
\hline Synedra tabulata (Ag.) Kütz. & $1-4$ & +++ & Cells 33-94 l., 4.0-5.5 b. & $\begin{array}{l}\text { Germain 1981, Aziz } \\
\text { and Ara } 2000\end{array}$ \\
\hline Synedra ulna (Nitzch) Ehr. & $1-4$ & +++ & Cells 320-350 l., 6.6 b. & $\begin{array}{l}\text { Islam and Chowdhury } \\
\text { 1979, Islam and } \\
\text { Irfanullah } 2005\end{array}$ \\
\hline $\begin{array}{l}\text { Synedra ulna var. oxyrhynchus } \\
\text { (Kütz.) van Heurek }\end{array}$ & $1-4$ & +++ & Cells 120-126 l., 14 b. & Islam and Haroon 1975 \\
\hline \multicolumn{5}{|c|}{ Order: Eunotiales, Family: Eunotiaceae } \\
\hline Eunotia lunaris (Ehr.) Grun. & $1-4$ & +++ & $\begin{array}{l}\text { Cells } 112.5 \text { l., } 7.2 \text { b. (at } \\
\text { the middle) }\end{array}$ & Islam and Haroon 1975 \\
\hline \multicolumn{5}{|l|}{ Family: Naviculaceae } \\
\hline $\begin{array}{l}\text { Gyrosigma acuminata (Kütz.) } \\
\text { Rab. }\end{array}$ & $1-4$ & +++ & $\begin{array}{l}\text { Cells } 139-165 \text { l., } 22.5- \\
25.0 \text { b. }\end{array}$ & Aziz and Islam 1986 \\
\hline $\begin{array}{l}\text { Gyrosigma acuminatum var. } \\
\text { lacustre Meist. }\end{array}$ & 1 & ++ & Cells 72.60 l., 14.52 b. & Islam and Haroon 1975 \\
\hline Navicula cryptocephala Kütz. & $2-4$ & ++ & Cells 25-35 l., 5-7 b. & $\begin{array}{l}\text { Germain 1981, Begum } \\
\text { and Hossain } 1993\end{array}$ \\
\hline Navicula cuspidata Kütz. & $1-4$ & +++ & $\begin{array}{l}\text { Cells } 47.2-165.5 \text { l., 16- } \\
32 \text { b. }\end{array}$ & $\begin{array}{l}\text { Germain 1981, Nahar } \\
2001 \text { (Pers. Comm.) }\end{array}$ \\
\hline Navicula decussis Oestrup & $1-4$ & +++ & Cells 16-25 l., 6-7 b. & $\begin{array}{l}\text { Germain. 1981, Begum } \\
\text { and Hossain 1993 }\end{array}$ \\
\hline Navicula menisculus Schum. & $1-2$ & +++ & Cells 28 l., 6-7 b. & $\begin{array}{l}\text { Islam and Haroon 1975, } \\
\text { Begum and Hossain } \\
1993\end{array}$ \\
\hline
\end{tabular}


(Contd.)

\begin{tabular}{|c|c|c|c|c|}
\hline Species & Stations & $\begin{array}{l}\text { Abun- } \\
\text { dance* }\end{array}$ & Dimension $(\mu \mathrm{m})$ & References \\
\hline \multicolumn{5}{|l|}{ Family: Naviculaceae } \\
\hline Navicula oblonga Kütz. & 1 & ++ & $\begin{array}{l}\text { Cells } 70-220 \text { l., } \\
13-24 \text { b. }\end{array}$ & Germain. 1981 \\
\hline $\begin{array}{l}\text { Navicula placentula (Ehr.) Grun. } \\
\text { var. rostrata Meyer }\end{array}$ & 3,4 & +++ & $\begin{array}{l}\text { Cells } 12.5-30.5 \text { l., } \\
8.5-10.0 \text { b. }\end{array}$ & $\begin{array}{l}\text { Germain. 1981, Aziz } \\
\text { and Tanbir } 1997\end{array}$ \\
\hline Navicula radiosa Kutz. & 3,4 & +++ & Cells 50-70 l., 7-8 b. & $\begin{array}{l}\text { Germain. 1981, Aziz } \\
\text { and Yasmin } 1997\end{array}$ \\
\hline $\begin{array}{l}\text { Pinnularia microstauron (Ehr.) } \\
\text { Cleve }\end{array}$ & 3,4 & +++ & Cells 60-90 l., 9-11 b. & $\begin{array}{l}\text { Germain 1981, Aziz } \\
\text { and Tanbir } 2003\end{array}$ \\
\hline Pinnularia viridis (Nitzsch) Ehr. & $1-3$ & +++ & Cells 30-200 l., 8-25 b. & $\begin{array}{l}\text { Germain 1981, Nahar } \\
2001 \text { (Pers. Comm.) }\end{array}$ \\
\hline \multicolumn{5}{|l|}{ Family: Cymbellaceae } \\
\hline Cymbella stuxbergii (Cl.) Cl. & $1-4$ & +++ & $\begin{array}{l}\text { Cells 50.0-68.9 l., } \\
18.0-21.7 \text { b. }\end{array}$ & $\begin{array}{l}\text { Islam and Haroon } 1975, \\
\text { Islam and Hossain } 1979\end{array}$ \\
\hline $\begin{array}{l}\text { Gomphonema lanceolatum fa. } \\
\text { turris (Ehr.) Hust. }\end{array}$ & $1-4$ & +++ & $\begin{array}{l}\text { Cells } 54.4-73.0 \text { l., } \\
\text { 12-15 b. }\end{array}$ & Islam and Haroon 1975 \\
\hline $\begin{array}{l}\text { Gomphonema olivaceum } \\
\text { (Hornemann) Kütz. }\end{array}$ & $1-2,4$ & ++ & $\begin{array}{l}\text { Cells } 45-48 \text { l., } \\
\text { 8.5-9.0 b. }\end{array}$ & Islam and Haroon 1975 \\
\hline \multicolumn{5}{|l|}{ Family: Bacillariaceae } \\
\hline Nitzschia acicularis W. Smith & $2-4$ & ++ & Cells 35-100 l., 3-5 b. & $\begin{array}{l}\text { Germain 1981, Nahar } \\
2001 \text { (Pers. Comm.) }\end{array}$ \\
\hline Nitzschia gracilis Hantz. & 3,4 & ++ & $\begin{array}{l}\text { Cells 10-112 l., } \\
4.0-5.52 \text { b. }\end{array}$ & $\begin{array}{l}\text { Germain 1981, Aziz } \\
\text { and Ara } 2000\end{array}$ \\
\hline $\begin{array}{l}\text { Nitzschia intermedia Hantz. } \\
\text { Grun. }\end{array}$ & $1,3-4$ & +++ & Cells 40-130 l., 4-6 b. & $\begin{array}{l}\text { Germain 1981, Begum } \\
\text { and Hossain } 1993\end{array}$ \\
\hline \multicolumn{5}{|l|}{ Family: Surirellaceae } \\
\hline $\begin{array}{l}\text { Suriella Robusta Ehr. } \\
\text { var. splendida (Ehr.) Van } \\
\text { Heurck. }\end{array}$ & $1-2$ & ++ & $\begin{array}{l}\text { Cells } 73.5-140 \text { l., } \\
22-52 \text { b. }\end{array}$ & $\begin{array}{l}\text { Islam and Haroon 1975, } \\
\text { Islam and Aziz } 1977\end{array}$ \\
\hline
\end{tabular}

\section{Acknowledgements}

The authors are grateful to late National Professor A.K.M. Nurul Islam, Department of Botany, University of Dhaka for identification of some diatoms.

\section{References}

APHA. 1976. Standard methods for the examination of water and waste water. (14th ed.) American Public Health Association, Washington. pp.1193.

Aziz, A. and M. Ara. 2000. Diatom taxa from deepwater rice fields at Tangail, Bangladesh. Bangladesh J. Plant Taxon. 7(1): 7-13.

Aziz, A. and A.K.M. Nurul Islam. 1986. Lagoon Algae of St. Martin’s Island, Bangladesh. Dhaka Univ. Stud. Part E. 1(1): 45-52.

Aziz, A. and M. Tanbir.1999. Newly recorded algal taxa from some northern districts of Bangladesh. I. Bluegreens. Bangladesh J. Bot. 28(1): 61-68. 
Aziz, A. and M. Tanbir. 2003. Algal flora of some northern districts of Bangladesh. Bangladesh J. Plant Taxon. 10(1): 63-77.

Aziz, A. and N. Yasmin.1997. Algal flora of Madhabkunda waterfall area in Moulvibazar, Bangladesh. I. Blue-green and red algae. Bangladesh J. Bot. 25(1): 9-18.

Begum, Z.N.T. 2008. A taxonomic account on the phytoplankton of a pond receiving textile industrial effluents. Bangladesh J. Plant Taxon. 15(2): 129-139.

Begum, Z.N.T. and M.Z. Hossain. 1993. Physico-chemical aspects and phytoplankton of a pond receiving textile industrial effluents. Dhaka Univ. J. Biol. Sci. 2(1): 93-99.

Bold, H.C. and M.J. Wynne. 1985. Introduction to the Algae. Prentice-Hall, New Jersey. pp. 1-706.

Germain, H. 1981. Flore Des diatomées. Diatomophycées Société Nouvelle Des éditions Boubée, Paris. pp. 1-444.

Gerrath, J. F. and P. Denny. 1979. Fresh water algae of Sierra Leone. 1. Euglenophyta. Nova Hedwigia 31: 525-585.

Hegde, G. R. and S.G. Bharati. 1986. Ecological Studies in ponds and lakes of Dharwad: occurrence of Euglenoid blooms. Phykos 25: 62-67.

Hickman, M. and I.D. Penn.1977. The relationship between planktonic algae and bacteria in a small lake. Hydrobiologia 53(2-3): 213-219.

Hynes, H.B.N. and F.T.K. Pentelow. 1978. The biology of polluted waters. Liverpool Univ. Press, Liverpool. pp. 202.

Islam, A.K.M. Nurul and M.A. Alfasane. 2002. Euglenophycease from Barisal District, Bangladesh. I Genus Phacus. Bangladesh J. Plant Taxon. 9(2): 3-18 .

Islam, A.K.M. Nurul and M.A. Alfasane. 2004. Euglenophyceae from Barisal district, Bangladesh: III. Genus Trachelomonas Ehr. Bangladesh J. Plant Taxon. 11(2): 33-37.

Islam, A.K.M. Nurul and A. Aziz. 1975. Study of marine phytoplankton from the northeastern Bay of Bengal, Bangladesh. Bangladesh J. Bot. 4(1-2): 1-32.

Islam, A.K.M. Nurul and A. Aziz. 1977. Studies on the phytoplankton of the Karnaphuli river estuary. J. Bangladesh Acad. Sci. 1(2): 141-145.

Islam, A.K.M. Nurul and A. Aziz. 1979. Algal flora of Moheshkhali Island, Bangladesh. Dacca Univ. Stud. Part B. 27(2): 105-122.

Islam, A.K.M. Nurul and Z.N.T. Begum. 1970. Studies on the phytoplanktons of Dacca District. J. Asiatic Soc. Pak. 15(3): 227-271 + pls. 8.

Islam, A.K.M. Nurul and A.R. Chowdhury. 1979. Hydrobiological studies of Dhanmondi lake, Dacca. II. Phytoplankton. J. Asiatic. Soc. Bangladesh (Sci.) 5(2): 47-57.

Islam, A.K.M. Nurul and A.K.Y. Haroon. 1975. Limnological studies of the river Buriganga II. Biological Aspect. Dacca Univ. Stud. Part B. 23(1): 25-44.

Islam, A.K.M. Nurul and M. Hossain. 1979. Preliminary studies on the algal flora of Bagerhat, Khulna. J. Asiatic Soc. Bangladesh (Sci.) 5(1): 37-45.

Islam, A.K.M. Nurul and H.M. Irfanullah. 2005. Hydrobiological Studies within the tea gardens at Srimangal, Bangladesh. III. Chlorophyceae (excluding desmids). Bangladesh J. Plant Taxon. 12(2): 19-37.

Islam, A.K.M. Nurul and M. Khatun. 1966. Preliminary studies on the phytoplanktons of polluted waters. Sci. Res. East Reg. Lab. Pakistan 3(2): 94-109.

Islam, A.K.M. Nurul and M. Khondker. 1997. New records of some flagellate algae for Bangladesh. 5. Chlamydomonas, Pascherina, Pyrobotrys, Cryptomonas and Chilomonas. Bangladesh J. Plant Taxon. 4(2): 13-23.

Islam, A.K.M. Nurul and K. Moniruzzaman. 1981. Contribution to the study on Euglenophyta of Bangladesh. I. Genus Trachelomonas Ehr. Int. Rev. ges. Hydrobiol. 66(1): 109-125.

Islam, A.K.M. Nurul and L. Nahar. 1967. Preliminary studies on the Phytoplanktons of polluted waters. Part II. Blue-green algae. Sci. Res. 4(2\&3): 141-149.

Islam, A.K.M. Nurul and M.A. Uddin. 1977. Blue-green algae from Dacca, Bangladesh. I. Chroococcaceae and Pleurocapsaceae. J. Asiat. Soc. Bangladesh (Sci.) 2(20): 75-81. 
Islam, A.K.M. Nurul and K.M. Zaman. 1975. Limnological studies of the river Buriganga III. Biological aspect. J. Asiatic. Soc. Bangladesh (Sci.) 1(1): 45-65.

Islam, A.K.M. Nurul, M. Khondker and S. Haque. 1991. Euglenoid algae of four polluted ponds in and around Dhaka city. Bangladesh J. Bot. 20(1): 7-15.

Johansen, D. 1940. Plant microtechnique. McGraw Hill Book Company Inc. N.Y. pp. 523.

Khondker, M., A.K.M. Nurul Islam and R. Islam. 1988. Studies on the primary productivity of Dhanmondi Lake. Dhaka Univ. Stud. Part E. 3(1): 15-21.

Khondker, M., A.K.M. Nurul Islam, Z.N.T. Begum. and S. Haque. 1990. Limnological studies of four polluted ponds in and around Dhaka city with reference to indicator species. Bangladesh J. Bot. 19(1): 51-63.

Khondker, M., R.A. Bhuiyan, J. Yeasmin, M. Alam, R.B. Sack, A. Huq, and R.R. Colwell. 2006. New records of phytoplankton for Bangladesh. 1. Cyanophyceae. Bangladesh J. Bot. 35(2): 173-179.

Palmer, C.M. 1959. Algae in water supplies. US Department of Health, Education and Welfare, Public Health Service, Cincinnati.

Patrick, R. 1973. Use of algae, especially diatoms, in the assessment of water quality. In: Biological methods for the assessment of water quality. ASTM.STP 528: 76-98.

Trainor, F.R. 1984. Indicator algal assays: laboratory and field approaches. In: Algae as ecological indicators. E. L. Schubert (Ed.). Academic Press Inc. pp. 434.

(Manuscript received on 16 March, 2009; revised on 27 May, 2009) 